\title{
COnE)-(OES
}

CIÊNCIA E TECNOLOGIA

\section{CONTRIBUIÇÕES DO PROJECT MODEL CANVAS NA REELABORAÇÃO DO PROJETO POLÍTICO PEDAGÓGICO}

\author{
Paula Trajano de Araújo Alves, Biatriz de Sousa Monteiro, Camila Mesquita Félix, \\ Andrea Moura da Costa SOUZA \\ Instituto Federal de Educação, Ciência e Tecnologia do Ceará \\ <paula.trajano15@gmail.com>,<byamonteiro18@gmail.com>.<camilafelix678@gmail.com> \\ $<$ andrea.souza@ifce.edu.br> \\ $10.21439 /$ conexoes.v15i0.2118
}

\begin{abstract}
Resumo. Este artigo discorre sobre uma metodologia de elaboração de projetos chamada Project Model Canvas (PMC) e teve como objetivo geral investigar como o PMC pode contribuir para o processo de elaboração ou reelaboração do Projeto Político Pedagógico (PPP). São objetivos específicos deste estudo: expor as orientações legais sobre a estruturação do PPP; compreender a composição e funcionalidade do PMC e apresentar o PMC como instrumento mediador na produção do PPP. Utilizou-se a abordagem qualitativa apresentando um caráter exploratório e utilizando-se da pesquisa bibliográfica e documental para a estruturação da investigação. É necessário ressaltar que, este estudo não possui a intenção de deslegitimar as diversas formas de desenvolvimento do Projeto Político Pedagógico, mas antes, carregou-se a intenção de apresentar uma alternativa simples, prática e possível de organização para a elaboração de um documento basilar no plano escolar. E assim, conforme a organização proposta pelo PMC, espera-se que essa metodologia contribua de modo eficaz para elaborar e reelaborar o PPP escolar.
\end{abstract}

Palavras-chaves: Projeto Político Pedagógico. Project Model Canvas;:Trabalho pedagógico.

\section{CONTRIBUTIONS OF PROJECT MODEL CANVAS IN THE REVELOPMENT OF THE PEDAGOGICAL POLITICAL PROJECT}

\begin{abstract}
This scientific study discusses a methodology for designing projects called Project Model Canvas (PMC) and aimed to investigate how the PMC can contribute to the process of elaboration or re-elaboration of the Pedagogical Political Project (PPP). The specific objectives of this study are: to expose the legal guidelines on the structuring of the PPP; understand the composition and functionality of the PMC and present the PMC as a mediating instrument in the production of the PPP. A qualitative approach was used, presenting an exploratory character and using bibliographical and documental research to structure the investigation. It is necessary to emphasize that this study does not intend to delegitimize the various forms of development of the Political Pedagogical Project, but rather, it was intended to present a simple, practical and possible organizational alternative for the preparation of a basic document in the school plan. And so, according to the organization proposed by the PMC, it is expected that this methodology will effectively contribute to the elaboration and re-elaboration of the school PPP
\end{abstract}

Keywords: Pedagogical Political Project; Project Model Canvas; Pedagogical work.

\section{INTRODUÇÃO}

O projeto político pedagógico - PPP se traduz como um dos principais documentos que elucidam a proposta educacional da instituição. O contexto histórico que possibilita o surgimento do Projeto Político Pedagógico se dá na década de 1980, em que começa-se a questionar um modelo de Estado que possui demasiado poder de decisão sobre diversas questões, inclusive e especialmente na escola, demonstrando assim, um padrão centralizado e vertical dos juízos.

$\mathrm{Na}$ esteira dessa conjuntura, no ano de 1988 ocorre o Fórum Nacional em Defesa da Escola Pública, em que os diálogos e a luta pela instituição de uma gestão democrática na escola pública são temas preponderantes do evento, na busca por garantir a autonomia das instituições de ensino. Apresentava-se uma realidade que urgia tais mudanças na organização da escola.

O fruto dessas discussões deságua na Constituição Federal de 1988, que instituiu legalmente a gestão democrática. No artigo 206, inciso VI, o documento nos traz que a "gestão democrática do ensino público, na forma da lei” (BRASIL, 1988) torna-se um dos princí- 
pios do ensino. Desta forma, legitima-se a participação da comunidade escolar (gestão, professores, pais) nos processos que envolvem decisões norteadoras da instituição, das quais o PPP é elemento vital.

No ano de 1996 foi promulgada a Lei de Diretrizes e Bases da Educação Nacional - LDB, n. ${ }^{\circ}$ 9.394/96. No documento, enfatiza-se o artigo 12 - inciso I - que estabelece como incumbência das escolas "elaborar e executar sua proposta pedagógica" (BRASIL, 1996) (BRASIL, 1996). Após as instituições legais dos termos que definem as responsabilidades oficiais da escola, compreende-se que a elaboração do PPP é de responsabilidade das instituições de ensino, seguindo as orientações e demandas de onde a mesma se encontra inserida. De maneira básica, é um documento que contempla as dimensões administrativa, financeira e pedagógica mantendo um diálogo com todos os envolvidos.

No seio desse diálogo, nascem as problemáticas relativas à construção ou reelaboração do Projeto Pedagógico. O cerne do documento, para além de uma exigência legal, é o compromisso do coletivo escolar com as ações do cotidiano e muito embora na teoria figure como algo de simples organização, na prática encontra diversos obstáculos de ordem administrativa, pedagógica e organizacional.

Diante da necessidade de reelaboração anual do PPP e da falta de recursos mediadores para a reconstrução deste documento, faz-se necessário a utilização de um instrumento que auxilie a comunidade escolar neste processo. Neste contexto, traz-se para o diálogo o Project Model Canvas - PMC, que no Brasil, foi criado no ano de 2013, a partir da ideia do suíço Alexander Osterwalder, o mesmo serviu-se de uma ferramenta de linguagem visual utilizando imagens e trouxe para descrever modelos de negócios dos diversos ambientes corporativos.

De maneira simplista o Canvas "é uma metodologia robusta, porém simples, de planejamento de projetos, que utiliza conceitos visuais da neurociência aliados a uma estrutura lógica de componentes que formam um plano de projeto" (CAMARGO, 2019). O intuito é trazer essa metodologia como uma alternativa para a melhoria e entendimento da construção ou reelaboração do PPP.

Neste sentido, o objetivo geral deste artigo aportouse em investigar como o PMC pode contribuir para o processo de elaboração ou reelaboração do Projeto Político Pedagógico (PPP). A fim de cumprir com este propósito, se faz necessário expor as orientações legais sobre a estruturação do PPP; compreender a composição e funcionalidade do PMC e apresentar o PMC como instrumento mediador na produção do PPP, estes se tra- duzem como os objetivos específicos deste estudo.

Mediante a proposta, utilizamos uma abordagem qualitativa do estudo, apresentando um caráter exploratório e utilizando-se da pesquisa bibliográfica e documental para a estruturação da investigação.

\section{O PROJETO PEDAGÓGICO ESCOLAR}

A Lei de Diretrizes e Bases da Educação (LDB, n ${ }^{\circ}$ 9.394, de 1996), especificamente no inciso I do artigo 12, descreve a responsabilidade da escola de auto coordenar e elaborar sua proposta pedagógica, que como tal, é compreendido como: o compromisso missional da escola, as etapas, níveis e modalidades que atenderá, conteúdos e disciplinas, bem como o processo de avaliação, métodos de ensino e materiais de apoio às ações didáticas e técnico-administrativas, dentre outros desdobramentos.

Ainda no artigo 12, no restante dos incisos, aponta observações relevantes para a elaboração e reelaboração do projeto: o inciso II, orienta quanto a assuntos com viés burocrático, ligados à administração das pessoas, enquanto recursos humanos, e gerenciamento dos recursos, estes tanto materiais, como financeiros. Já no III, orienta a delimitação e cumprimento dos dias letivos e horas-aulas estipuladas. O inciso IV, foca no cumprimento e participação do professor no plano de trabalho, isso no contexto geral, e em seus planos específicos. Os demais, V, VI, VII e VIII, trata da relação de parceria e contribuição democrática entre escola e seus pares, ponto de grande relevância para construção do projeto pedagógico escolar, como se verá adiante.

No artigo 13, em seus incisos I e II definem e descrevem mais especificamente o que o inciso IV do artigo anteriormente citado orienta. Primeiro, descrevendo a incumbência docente em participar da elaboração da proposta pedagógica ou projeto pedagógico, bem como da elaboração e cumprimento do plano de trabalho (BRASIL 2017). Conforme Veiga (2009), há uma ressalva necessária para distinguir, proposta pedagógica, projeto pedagógico e plano de trabalho, os primeiros, proposta e projeto, referem-se ao trabalho pedagógico da escola, já o plano de trabalho relacionase às minudências da proposta ou projeto, e se desdobram em plano de ensino, plano de atividades, tanto de responsabilidade docente, como as do corpo técnicoadministrativo.

Nessa perspectiva de papéis e contribuições, é válido ressaltar os princípios destacados no artigo 14, em seus incisos I e II, sobre o estabelecimento e fortalecimento da gestão democrática enquanto norteadora da construção do projeto pedagógico, os mencionados incisos, asseguram a efetiva participação dos sujeitos que 
permeiam o ambiente escolar na elaboração e nas atividades concernente aos conselhos escolares e equivalentes. Sobre a construção, Veiga (2009) enfatiza que a responsabilidade de construir, executar e avaliar é da escola, porém cabe ao corpo diretivo e equipe escolar gerenciar essa construção, os corresponsáveis, de acordo com a autora, são os professores, pais e responsáveis, alunos, pessoal técnico-administrativo, e demais segmentos do corpo social.

Para a construção ou reconstrução dessa identidade, Padilha (2002) assinala três aspectos: os princípios, as estratégias concretas e o trabalho coletivo. Betini (2005), por sua vez, caracteriza de forma mais específica essa (re) construção, de acordo com o autor, o PPP é a idealização do fazer onde se define na instituição “[...] seus objetivos, metas e estratégias permanentes, tanto no que se refere às suas atividades pedagógicas, como as funções administrativas" (BETINI, 2005, p. 38). Desse modo, o PPP indica os rumos que a escola deverá prosseguir, o que ela é, e o que será, a partir da atividade coletiva.

Betini (2005, p. 38, grifo nosso) define cada um dos "P" da sigla PPP, entendendo que é chamado de Projeto por "[...] passa a ser a direção ou rumo para as ações da escola. " Político, pois espelha as alternativas e preferências de lugares e possibilidades na formação dos sujeitos, como integrantes atuantes e capazes de remodelar a realidade em que vive. No âmbito Pedagógico refere-se às ações de ordem pedagógicas e didáticas que fazem com que a instituição escolar cumpra seus objetivos educacionais. Enquanto norteador da missão e trabalho da instituição escolar, o PPP deve assumir a responsabilidade pelo andamento do planejamento escolar, "[...] em um movimento constante de reflexão-açãoreflexão." (BETINI, 2005, p. 38). Pois não se entende o documento como um mero cumprimento de obrigação normativa, mas como uma delimitação e proposição, a partir da realidade da instituição, que se dá de forma coletiva, sendo constantemente ajustado e reelaborado para cumprir os objetivos a que se propõe.

É nesta premissa, que Veiga (2009, p. 164), postula que "[...] a escola deve assumir, como uma de suas principais tarefas, o trabalho de refletir sobre sua intencionalidade educativa. " Pois, o documento constituise como identidade e para tanto precisa ser condizente com o que ali é representativo, e isso perpassa a simples definição das disciplinas, conteúdos e objetos de conhecimento. Isso envolve a instituição como um todo, inclusive os sujeitos que a cercam. Neste sentido, reafirma-se, a partir da fala de Cândido e Gentilini (2017, p. 331), que

$$
\text { [...] o PPP não deve ser apenas um documento que }
$$

\begin{abstract}
serve a propósitos burocráticos e ao final ficar engavetado, mas, sim, exercer um poder de direção sobre aqueles que fazem a escola em seu cotidiano. A escola, portanto, deve se reunir com frequência para repensar as ações do Projeto, atualizando as proposições de acordo com os acontecimentos e pensamentos daqueles que estão envolvidos.
\end{abstract}

Com isto, percebe-se a importância do PPP enquanto documento normativo e identitário das instituições escolares, notando assim, que em sua construção e reconstrução carrega todo a delimitação pedagógica, humana, material e financeira das instituições, e tendo em vista a mutabilidade de tais coisas, a uma constante necessidade de atualizações e modificações, que não podem ser deixadas de lado, pois como descreveuse aqui, o PPP carrega o que a escola representará, o que a escola é, e o que ela desenvolverá. Dessa forma, é de suma importância sua edição, e está não apenas anualmente, como cobrança dos setores administrativos, como as secretarias e distritos de educação, mas como um constante ato de ação-reflexão-ação e revisão do trabalho educativo e social da instituição escolar.

\section{CAMINHO METODOLÓGICO}

O presente estudo de abordagem qualitativa, que conforme Bastos (2005, p. 40) permite "[...] maior preocupação com o aprofundamento e abrangência da compreensão dos dados. "Se construiu sobre o viés descritivo na busca de categorizar e explicar os acontecimentos, constituindo-se também como exploratório, pois “[...] procura aprimorar ideias, [...] ajuda na formulação hipóteses e [...] contribui com aquisição de embasamento para realizá-las" (BASTOS, 2005, p. 41 e 42).

Quanto a sua tipologia, fez-se o uso da pesquisa bibliográfica, que em concordância com Bastos (2005), permite inferências sobre um determinado problema, a partir de referências teóricas, que contribuíram como aporte teórico sobre o Projeto Político Pedagógico, utilizando-se das referências: Betini (2005), Cândido e Gentilini (2017), Padilha (2002), Veiga (2009). No que concerne o Project Model Canvas fez-se uso da bibliográfica com os seguintes autores: Ferreira e Ota (2018), Silva et al. (2015), Araújo (2015). O estudo caracterizase também como pesquisa documental, pois fez uso de documentação primária, como é o caso da Lei de Diretrizes e Bases da educação nº 9.394, de 1996, para descrição e respaldo legal no que concerne a elaboração do PPP nas instituições escolares. E do Guia definitivo (s/a) de instruções do Project Model Canvas para conceituar e descrevê-lo.

A pesquisa pretende apresentar o Project Model Canvas como facilitador da elaboração/reelaboração do 
PPP nas instituições escolares, mostrando por meio de quadros de sínteses e da redação de texto como tal ferramenta se mostra relevante no cenário educacional, especificamente, na tarefa de auxiliar os sujeitos envolvidos no processo coletivo de elaboração do PPP.

Deste modo, a seguir têm-se a construção teórica dividida em apresentar e descrever o Projeto Político Pedagógico em sua delimitação normativa, conceitos, estruturação e reflexões necessárias sobre sua elaboração e sua reelaboração. O Project Model Canvas em sua conceituação, estruturas específicas e considerações indispensáveis. Em seguida dar-se continuidade com a estrutura de analisar e discutir a relação entre ambos, apontando como o Canvas pode auxiliar na exposição e simplificação do processo de (re) construção do PPP. Por fim, tece-se algumas considerações sobre a experiência e pontua-se sobre as reflexões que surgiram e as que podem surgir em pesquisas futuras.

\section{PROJECT MODEL CANVAS}

O Project Model Canvas surge da necessidade encontrada em alinhar comunicação e gerenciamento coletivo, ele foi elaborado por José Finocchio e concebido em parceria com o Project Builder no Aplicativo Canvas APP. A sua organização tem como inspiração os conhecimentos da Neurociência, Design Thinking e a experiência do criador com metodologias de projetos. Consiste em um modelo mental de plano, sua estrutura divide-se em três partes: 1) o Canvas, que é a sua representação visual, ou seja, o suporte onde é vinculado; 2) as perguntas fundamentais, por quê? O quê? Quem? Como? Quando e Quanto?; 3) e os Posts, que são as descrições curtas e possíveis de serem ajustadas colocadas em formato de post-it no Canvas. Vejamos a Figura 11. observa-se a estrutura e o layout básico do PMC.

Sendo assim, na imagem acima visualizamos os componentes básicos do Project Model Canvas e que servem de base para o planejamento de qualquer projeto, seja ele profissional ou até pessoal. Importante ressaltar que tanto no planejamento quanto na execução do projeto podem ser acrescidas outros Posts no quadro de representação visual do projeto (Canvas) por isso que o Project Builder recomenda que o Canvas seja preenchido com post-it pois eles podem ser modificados sempre que necessário. Sendo assim, essa dinamicidade e mobilidade do mapa mental que compõe o Canvas contribui valorosamente para o desenvolvimento organizado de qualquer projeto. A seguir, na Tabela 1 uma síntese apresentando a função de cada uma das partes estruturais do PMC.

Pelo que foi exposto na Tabela 1, a utilização do Canvas contempla todas as etapas de desenvolvimento de um projeto, respondendo de maneira mentalmente organizada e interconectada todas as etapas do projeto (por quê, o quê, quem, como, quando e quanto). Responder essas perguntas é de suma importância para se obter um resultado eficiente ao final do projeto com a entrega do produto.

Por meio de sua delimitação, conforme o Guia definitivo do Canvas, há um aprimoramento da capacidade de planejamento, o mesmo, ainda conforme o Guia (s/a, p. 04), “[...] é uma metodologia robusta de gerenciamento de projetos". Mas ainda, mesmo condensando essa robusta descrição, ele manifesta-se como um facilitador da elaboração e visualização das partes do projeto, a partir da coletividade dos seus agentes envolvidos.

De acordo com Silva et al. (2015) a ideia principal do PMC “[...] é simplificar e desburocratizar o plano de gerenciamento de projeto. "Para isso vai utilizar-se da inspiração na neurociência se valendo de diferentes recursos visuais, tendo como principal motivação " [...] fornece às pessoas envolvidas o entendimento das relações entre os conceitos do projeto" (SILVA et al. 2015. p. 3). Tornando visível com isto, que entre suas ideias e motivações principais, o Canvas visa elaborar de modo mais harmonioso e simplificado o plano, claro que com suas devidas complexidades, mas tentando, por meio das inspirações e recursos supracitados, descomplexificar o caminho. E atuando coletivamente, fazendo dos envolvidos no processo participantes ativos e conscientes de toda a elaboração e exposição.

Neste sentido, Araújo (2015, p. 29) pontua que “[...] o PMC irá priorizar a simplificação das ações que deverão ser feitas, proporcionando um pensamento conjunto de equipe e envolvidos. Em outras palavras, o PMC é construído numa perspectiva de compartilhamento e de sua execução participativa dos envolvidos. "Envolto em um processo sequencial que permite uma visão ordenada de todos os objetivos do plano. Apostando nos recursos da neurocognição que alarga a percepção atada na construção de conceitos. Assim, "[...] composto de cinco etapas construídas em blocos separados e dispostos num plano visual, reunindo informações que de fato serão pertinentes ao projeto, organizando e integrando as informações, este é o PMC" (ARAúJO, 2015, p. 29).

\section{APLICAÇÃO DO CANVAS NA CONSTRU- ÇÃO DO PPP}

O PMC surge aqui como um facilitador da elaboração e reelaboração do Projeto Político Pedagógico, pois no contexto de sua concepção encontrou-se pontos em comum e que foram enxergados como facilitadores e integradores dessa construção. Percebe-se no cenário escolar uma resistência e inclusive a negligência 
Figura 1: Competência como fonte de valor para o indivíduo e para a organização.

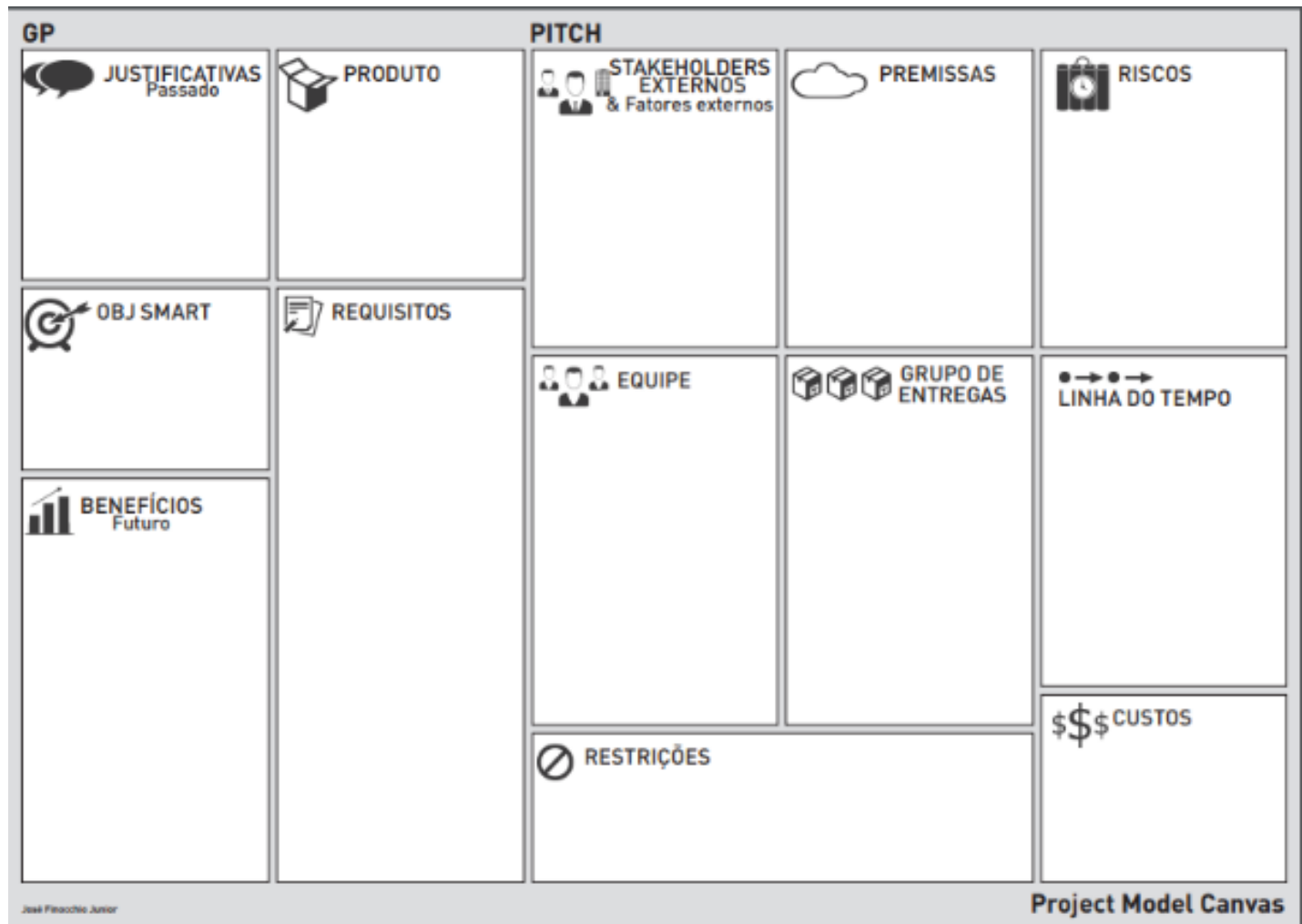

Fonte: Project Builder (2021).

ao documento PPP, que como discutido anteriormente, configura-se como o documento central da escola, pois dele deriva-se todo o plano de missão, visão e trabalho da escola. Será perceptível, por meio das descrições a seguir, que o PMC pode atuar diretamente no auxílio da compreensão visual do documento e pela valorização e atualização do PPP.

Nesse sentido, esta seção apresenta na prática como o Project Model Canvas pode ser aplicado no processo de (re) elaboração do Projeto Político Pedagógico. Com base na delimitação feita por Ferreira e Ota (2018), o PMC é uma forma de conceber um plano de projetos, e este, construído sobre um viés colaborativo, de modo que haja integração entre os integrantes; essa concepção combina perfeitamente com a ideia de gestão democrática e trabalho coletivo sobre o qual o PPP deve ser concebido. Vejamos a seguir, Tabela 2, o exemplo aplicado levando em consideração o contexto de uma escola da rede municipal do município de Fortaleza/Ceará.

Como se pode perceber no Tabela 2, o PMC pode sim contribuir na condução do projeto de revisão e atualização do PPP pois, o layout Canvas permite visualizar e planejar todas as etapas do referido projeto, permi- tindo inclusive prever riscos que podem surgir ao longo do desenvolvimento das tarefas. Outro ponto que também pode ser destacado é que a adoção do Canvas pode servir de padrão para projetos futuros da escola e assim, a escola terá sempre uma referência para planejamento de projetos. É importante ressaltar ainda que partimos do princípio, nessa descrição do Tabela01, que o Diretor da escola estará na função de Gerente do Projeto pois é ele que vai, com a devida colaboração da equipe de coordenadores, organizar e conduzir as reuniões, bem como oficializar para a Secretaria Municipal de Educação - SME a versão final do PPP que no caso em questão, irá se configurar como o Produto do projeto.

Outra explicação necessária sobre a simulação disposta no Tabela 2 é sobre a seção Linha do Tempo, pois, como se pode perceber, ela estará composta de vários momentos de acordo com o Grupo de Entregas e a divisão de tempo necessária para a construção do produto. Vale ressaltar ainda que como a escola é subordinada à SME corre, portanto, o risco de acontecerem eventos imprevistos no calendário escolar e assim a SME orientar que a escola adie ou suspenda o cronograma de reuniões. 


\begin{tabular}{|c|c|c|}
\hline \multicolumn{3}{|c|}{$\begin{array}{l}\text { GP = Gerente de Projeto: Responsável geral pelo desenvolvimento do projeto. } \\
\text { PITCH: Frase que resume o projeto }\end{array}$} \\
\hline & POSTS & FUNÇÃ̃O \\
\hline \multirow{3}{*}{ Por quê } & Justificativa & $\begin{array}{l}\text { Identifica o problema e as necessidades que fundamentam } \\
\text { o desenvolvimento do projeto. }\end{array}$ \\
\hline & Objetivo Smart & $\begin{array}{l}\text { Determina o propósito do projeto; isto de maneira específica, } \\
\text { mensurável, atingível, realista e temporizável. }\end{array}$ \\
\hline & Benefícios & Descreve as vantagens do projeto. \\
\hline \multirow[t]{2}{*}{ O quê } & Produto & $\begin{array}{l}\text { Resultado final do projeto. Pode ser um produto físico } \\
\text { (concreto) ou um serviço. }\end{array}$ \\
\hline & Requisitos & $\begin{array}{l}\text { Apresenta ao leitor as partes fundamentais necessárias } \\
\text { para o desenvolvimento do projeto. }\end{array}$ \\
\hline \multirow[t]{2}{*}{ Quem? } & Stakeholders & $\begin{array}{l}\text { Pessoas e/ou instituições parceiras no desenvolvimento do } \\
\text { projeto, mas que não estão subordinadas ao gerente do projeto. }\end{array}$ \\
\hline & Equipe & Participantes responsáveis por produzir as entregas do projeto. \\
\hline \multirow{3}{*}{ Como? } & Premissas & $\begin{array}{l}\text { São suposições dadas como certas e favoráveis ao } \\
\text { desenvolvimento do projeto. }\end{array}$ \\
\hline & Grupo de entregas & $\begin{array}{l}\text { Componentes gerados ao longo do desenvolvimento do projeto. } \\
\text { São as partes mensuráveis e tangíveis que vão sendo entregues } \\
\text { e que ao final resultarão no produto. }\end{array}$ \\
\hline & Restrições & São as limitações do projeto. \\
\hline \multirow{3}{*}{ Quando e Quanto? } & Riscos & $\begin{array}{l}\text { Fatores externos ocasionais que podem comprometer } \\
\text { o desenvolvimento do projeto. }\end{array}$ \\
\hline & Linha do tempo & $\begin{array}{l}\text { Períodos em que vão ocorrer as entregas que comporão } \\
\text { o projeto. }\end{array}$ \\
\hline & Custos & Valor que será gasto para concluir o projeto. \\
\hline
\end{tabular}

\section{CONSIDERAÇÕES FINAIS}

A pretensão de investigar as formas como o PMC pode ser um facilitador, apresentando-se com alternativas práticas e satisfatórias no processo de elaboração e reelaboração do PPP, culminou numa apresentação composta pela linguagem visual que se mostra por meio de imagens e pontos sintéticos que elucidam a praticidade do instrumento em organizar o planejamento, estando dividido em partes, onde traça-se elementos para a composição do documento.

Como observado ao longo do texto o PPP configurase como um documento normativo de caráter local e inerente a cada instituição, ele é a elucidação da proposta educacional, tanto no que concerne a organização pedagógica, como física/administrativa das instituições escolares. Dado a relevância para a instituição de tal composição, a LDB, emprega a escola a responsabilidade de elaborar/reelaborar, executar e regular este documento. Com base nas dificuldades, revelou-se neste estudo, o de elaboração e reelaboração do documento, sendo por vezes até negligenciado, apresentou-se, assim, o PMC como mediador para essa construção.
Com os recursos do PMC encontrou-se a forma de lidar com a complexidade da elaboração do documento, visto que a problemática, por vezes, está ligada a visualização daquilo que se pretende fazer, assim, identificou-se na ferramenta a linguagem e exposição necessária, considerando também, que em sua constituição, o PMC, se concebe por meio de uma proposta colaborativa de projetos e integração entre os integrantes, o que coerentemente liga-se ao PPP, por, do mesmo modo, orientar em sua composição o trabalho democrático e participativo na sua elaboração e reelaboração.

Desta forma, ao apresentar o Canvas como alternativa na construção ou atualização do PPP, foi possível delimitar uma sequência de ações que permitiram: visualizar e planejar todas as etapas pelas quais perpassa a construção; delimitar as funções e tarefas a serem concretizadas, dentro de prazos possíveis, considerando inclusive imprevistos; dividir e coordenar as equipes que participaram, levando em consideração o trabalho colaborativo que permite que se integrem e validem a exigência de concepção do documento sobre um viés democrático, assim como, definindo as funções e distribuindo as equipes, pois a composição soma concepção 




e trabalho, tanto pedagógico, como também administrativo. E ainda não menos importante, mostrou-se como ferramenta padrão para futuros projetos da escola.

Diante do exposto, é necessário ressaltar que a intenção não é limitar a construção ou criticar as demais formas de elaborar e reelaborar o documento PPP, mas apresentar uma alternativa que poderá, por meio de seus recursos, ser um facilitador para cumprimento das exigências delegadas às instituições. Urge nesse sentido, alargar esta discussão, e tê-la como um ponta pé, para acrescer a temática, buscando novas alternativas, ou, o aperfeiçoamento desta, que aqui não é visualizada como acabada, mas como um esboço daquilo que, por meio, do Canvas ainda se pode traçar.

\section{REFERÊNCIAS}

ARAúJO, A. B. Aplicação do Project Model Canvas no planejamento de projetos monográficos na graduação. Dissertação (Monografia, Departamento de Administração) — Universidade Federal do Rio Grande do Norte, Natal, 2015.

BASTOS, N. M. G. Introdução à metodologia do trabalho acadêmico. 1. ed. Fortaleza: Edição Própria, 2005.
BETINI, G. A. A construção do projeto políticopedagógico da escola. 2005. Disponível em: <http://www.escolapadrereus.com.br/portal/JP/JP texto_01.pdf.> Acesso em: 17 mai. 2021.

BRASIL. Constituição da República Federativa do Brasil. 1. ed. Brasília: Senado Federal: Centro Gráfico, 1988.

Lei de diretrizes e bases da educação nacional. 1996. Disponível em: <http://www.planalto.gov.br/ ccivil_03/leis/19394.htm> Acesso em: 16 out. 2021.

\section{CAMARGO, R. Project Model Canvas para} gerenciamento de projetos. 2019. Disponível em: <https://robsoncamargo.com.br/> Acesso em: 07 jun. 2021.

CâNDIDO, R. D. K.; GENTILINI, J. A.

Base Curricular Nacional: reflexões sobre autonomia escolar e o Projeto Político-

Pedagógico. 2017. Disponível em: <https: //www.seer.ufrgs.br/rbpae/article/view/70269/43509> Acesso em: 05 jun. 2021.

FERREIRA, T. C.; OTA, M. A. Contribuições do Project Model Canvas no Gerenciamento de cursos online: do planejamento às etapas de execução. 2018. Disponível em: <https: 
//www.researchgate.net/publication/329579533_

Acesso em: 07 jun. 2021.

PADILHA, P. R. Planejamento dialógico: como

construir o Projeto Político Pedagógico da escola. 2.

ed. São Paulo: Cortez, 2002.

Project Builder. Guia Definitivo do Projec

Model Canvas. 2021. Disponível em: <https:

//www.projectbuilder.com.br/Downloads/

Guida-Definitivo-do-Project-Model-Canvas.pdf>

Acesso em: 06 jun. 2021.

SILVA, S. V.; SILVA, L. B. da; SALES, M. S.;

FERNANDES, F. A.; SALES, P. P. R. Uma ferramenta para auxiliar a utilização do project model canvas. In:

XI Congresso Nacional de Excelência em Gestão.

Rio de Janeiro: FIEB, 2015. p. 1-14.

VEIGA, I. P. A. Projeto político-pedagógico e gestão democrática: novos marcos para a educação de qualidade. Retratos da Escola, v. 3, n. 4, p. 163-171, 2009. 